Research, Society and Development, v. 9, n. 4, e167943052, 2020

(CC BY 4.0) | ISSN 2525-3409 | DOI: http://dx.doi.org/10.33448/rsd-v9i4.3052

A teoria crítica e o debate sobre microemancipação

Critical theory and the debate about microemancipation

Teoría crítica y debate sobre microemancipación

Recebido: 08/03/2020 | Revisado: 09/03/2020 | Aceito: 10/03/2020 | Publicado: 20/03/2020

\title{
Leonardo Alexandrino de Almeida
}

ORCID: https://orcid.org/ 0000-0002-7165-0452

Universidade Federal do Espírito Santo, Brasil

E-mail: admleonardoufjf@gmai.com

Richardson Moro Schmittel

ORCID: https://orcid.org/0000-0003-1657-2938

Universidade Federal do Espírito Santo, Brasil

E-mail: richardson.moro@gmail.com

\section{Resumo}

Este ensaio tem por objetivo analisar o debate sobre microemancipação difundido nos Critical Management Studies, confrontando com os objetivos da teoria crítica no que se refere à emancipação. Metodologicamente buscou-se observar as orientações de Meneghetti (2011) e Bertero (2011) que apresentam reflexões sobre a produção de ensaios no campo dos estudos organizacionais. O conceito de emancipação para teoria crítica é retomado a partir de autores da Escola de Frankfurt. O conceito de microemancipação é discutido a partir do trabalho de Alvesson e Willmott (2010). Posteriormente, é analisado o debate entre intelectuais brasileiros sobre o conceito de microemencipação e sua aderência ao propósito de emancipação presente na teoria crítica. Por fim, argumenta-se que a aceitação do conceito de microemancipação, não implica a negação do ideal de emancipação preconizado pela teoria crítica, ainda que o conceito seja, em alguns casos, utilizado de forma prejudicial ao propósito emancipatório da crítica.

Palavras-chave: Teoria Crítica; Critical Management Studies; Escola de Frankfurt.

\footnotetext{
Abstract

This essay aims to analyze the debate on microemancipation widespread in Critical Management Studies, confronting the objectives of critical theory with regard to emancipation. Methodologically, we sought to observe the guidelines of Meneghetti (2011) and Bertero (2011) that present reflections on the production of essays in the field of organizational studies. The concept of emancipation for critical
} 
theory is taken up again from authors of the Frankfurt School. The concept of microemancipation is discussed from the work of Alvesson and Willmott (2010). Later on, the debate among Brazilian intellectuals about the concept of microemancipation and its adherence to the purpose of emancipation present in critical theory is analyzed. Finally, it is argued that the acceptance of the concept of microemancipation does not imply the negation of the ideal of emancipation advocated by critical theory, even if the concept is, in some cases, used in a way that is detrimental to the emancipatory purpose of criticism.

Keywords: Critical Theory; Critical Management Studies; Frankfurt School.

\section{Resumen}

Este ensayo pretende analizar el debate sobre la microemancipación generalizado en los estudios de gestión crítica, confrontando los objetivos de la teoría crítica con respecto a la emancipación. Metodológicamente, hemos tratado de observar las directrices de Meneghetti (2011) y Bertero (2011) que presentan reflexiones sobre la producción de ensayos en el ámbito de los estudios de organización. El concepto de emancipación para la teoría crítica es retomado por los autores de la Escuela de Frankfurt. El concepto de microemancipación se discute a partir del trabajo de Alvesson y Willmott (2010). Más adelante se analiza el debate entre los intelectuales brasileños sobre el concepto de microemancipación y su adhesión al propósito de emancipación presente en la teoría crítica. Por último, se argumenta que la aceptación del concepto de microemancipación no implica la negación del ideal de emancipación propugnado por la teoría crítica, aunque el concepto se utilice, en algunos casos, de manera perjudicial para el propósito emancipador de la crítica.

Palabras clave: Teoría Crítica; Estudios de Gestión Crítica; Escuela de Frankfurt.

\section{Introdução}

Na década de 1930 seria pouco provável que alguma corrente teórica ousasse questionar o paradigma hegemônico nas ciências sociais que era inspirado pelo sucesso do desenvolvimento das ciências da natureza. Os teóricos idealizavam uma ciência social com características semelhantes àquelas que garantiam o reconhecimento das ciências duras. Entretanto, não obstante os esforços empreendidos, ter o positivismo como paradigma hegemônico não permitiu o desenvolvimento esperado nas ciências sociais, o que contribuiu para o desenvolvimento da teoria crítica. O debate entre teoria tradicional e teoria crítica é tema desde os primeiros estudos de Horkheimer (1975), porém, o que talvez nem os críticos esperassem fosse o surgimento de um debate sobre o conceito de emancipação e microemancipação, nos chamados Critical Management Studies (CMS), área influenciada pela 
teoria crítica. Esse ensaio tem por objetivo analisar o debate sobre microemancipação, difundido nos CMS, confrontando com os objetivos da teoria crítica no que se refere à emancipação.

O caminho para compreender esse debate inicia-se pela definição do que é uma teoria, que pode ser compreendida como uma declaração de conceitos inter-relacionados que mostram como um fenômeno ocorre, ou seja, como um arcabouço de conhecimentos que explica a ocorrência de determinados fatos (Corley \& Gioia, 2011), ou, como um conjunto ordenado de afirmações sobre um comportamento genérico (Weick, 1989). A construção dessas teorias é guiada por uma corrente epistemológica, e, até a década de 1930, os estudos organizacionais eram desenvolvidos à sombra da tradição científica das ciências exatas, como a matemática, física e química, que emprestaram seus métodos e fórmulas para desenvolver as teorias relacionadas às ciências sociais, como explicado por Horkheimer (1975). Essa forma de desenvolver teorias foi chamada por Horkheimer de Teoria Tradicional (Horkheimer, 1975).

Horkheimer identificou que os métodos da teoria tradicional não seriam adequados para resolver uma série de questões sociais, passando a defender então o que chamou de Teoria Crítica. O estudioso encontrou ambiente propício para desenvolver sua teoria na Frankfurt do século XX, pois tinha apoio da burguesia e um clima intelectual adequado à época. Quando assumiu a direção do Instituto para a Pesquisa Social em 1930 apresentou seu programa para teoria crítica em seu discurso inaugural, o que deu início ao seu trabalho junto a Herbert Marcuse (Honneth, 1999), emergindo então, em contraposição à teoria tradicional, a teoria crítica, que passou a ser uma alternativa epistemológica para os estudos em ciências sociais. Sob influência inicial da obra de Karl Max, a teoria crítica se caracteriza, entre outros aspectos, pela proposta de emancipação, presente desde os primeiros trabalhos da chamada escola de Frankfurt.

Embora as ciências sociais tenham influenciado diretamente os estudos organizacionais, a incorporação da teoria crítica nesse campo de estudos não ocorre na mesma proporção que a teoria tradicional (Alvesson \& Willmott, 2010), e buscando maior aceitação de estudos críticos no campo dos estudos organizacionais, Alvesson e Willmott (2010) apontam alguns motivos para a pouca difusão de estudos críticos nesse campo propondo como solução, entre outros pontos, a adoção do conceito de microemancipação.

O debate em torno do tradicional conceito de emancipação presente na teoria crítica e o conceito de microemancipação propostos por Alvesson e Willmott (2010) será o foco deste ensaio, que, conforme já abordado, tem por objetivo analisar o debate sobre microemancipação, difundido nos CMS, confrontando com os objetivos da teoria crítica no que se refere à 
emancipação. Entretanto, antes de entrar propriamente no debate, faz-se necessário discorrer brevemente sobre a teoria crítica e a centralidade do conceito de emancipação, bem como sobre os estudos críticos em administração e a emergência do conceito de microemancipação.

\section{Metodologia}

O presente trabalho foi construído em forma de ensaio. Meneghetti (2011) afirma que o ensaio requer sujeitos abertos a formas diferentes do métodos tradicionais das ciências. $\mathrm{O}$ autor destaca que no ensaio teórico o conteúdo é mais relevante que a forma e esta pode assumir diferentes facetas. Bertero (2011) complementa a visão de Meneghetti (2011) destacando que no ensaio não há uma quebra da dicotomia entre sujeito e objeto, mas a internalização do objeto pelo sujeito é que permite reflexões úteis para o avanço teórico.

A partir da reflexão destes autores este ensaio foi construído resgatando a centralidade da ideia de emancipação na teoria crítica e o debate sobre microemancipação para refletir sobre o impacto da disseminação desse conceito nos CMS para o ideal emancipatório que deu origem à escola de Frankfourt.

\section{Breve Relato sobre Teoria Crítica}

A subordinação das ciências sociais à teoria tradicional continuou se enfraquecendo na década de 1950, onde existiam críticas sobre a replicação das metodologias e previsões abrangentes das ciências naturais para as ciências sociais, o que oportunizou a criação de uma série de perspectivas concorrentes. Esse distanciamento da teoria tradicional não significaria necessariamente um caminho para a crítica, mas foi isso que ocorreu (Fournier \& Grey, 2000). Observando o ambiente de trabalho, quase não era mais possível distinguir o que era natural e o que era pertencente à práxis social, pois mesmo a experiência com o natural era influenciada pela práxis, logo seria necessário uma busca por uma ressignificação da ciência (HORKHEIMER, 1975).

Essa tradição filosófica também é questionada por Habermas (1975), pois apesar de entender essa tradição como útil sob o ponto de vista metodológico, a teoria tradicional deveria perder sua relevância com o tempo, por não conseguir explicar elementos da subjetividade humana, como ascendia nos estudos fenomenológicos à época, logo, Habermas também estava empenhado para uma ressignificação das bases teóricas da ciência.

Em busca dessa ressignificação, a teoria crítica propôs maior autonomia aos indivíduos 
e forneceu uma base intelectual para isso, mesmo imersa no ambiente econômico tecnocrata e industrial da sociedade da época. Os indivíduos aceitavam essa realidade convenientemente, mas, com o surgimento da teoria crítica, foram encorajados a alterá-la para que ela não se perpetuasse, pois, essa realidade era tida como exploratória e dominadora. A teoria crítica foi desenvolvida então baseada no pressuposto de que a ideologia positivista, base da teoria tradicional, havia ido além do limite da ciência, prejudicando os indivíduos que, em busca de uma maior capacidade produtiva, se prejudicavam e não deveriam concordar com a perpetuação do mundo como ele se apresentava (Alvesson \& Willmott, 2010).

A teoria crítica como proposta por Horkheimer, visava representar sentimentos e representações de uma classe, não necessariamente se opondo à teoria tradicional, mas a questionando como método único para o conhecimento científico. Horkheimer partiu da premissa de que a teoria tradicional possui um caráter utilitarista voltado para a produção, e esse caráter, que norteava os conceitos de melhor, útil, conveniente, produtivo, entre outros, guiava o comportamento dos indivíduos que aceitavam a realidade na qual estavam inseridos de maneira acrítica (Horkheimer, 1975).

Um dos argumentos de Horkheimer (1975) para defender a teoria crítica era de que a razão deveria tornar os indivíduos racionais, críticos, mas essa razão guiada pela teoria tradicional poderia cegar o homem, não o permitindo compreender a realidade e sendo facilmente persuadido pelo, logo, caberia à teoria crítica resgatar a criticidade, tornando os indivíduos conhecedores da história, da vida social e da economia e os tornando agentes de transformação da própria realidade. Isso significa que os indivíduos não deveriam acreditar cegamente na razão que era imposta a eles, pois essa razão era sempre concebida de forma atraente e sedutora para convencê-los e impedi-los de, por meio da crítica, compreender a realidade, alcançar a autonomia e emancipar-se.

No que diz respeito ao contexto histórico da teoria crítica, observa-se que, num primeiro momento, Horkheimer reforçou a necessidade de desenvolvê-la explicando que os recursos e métodos que serviam a teoria tradicional eram de propriedade das classes dominantes, logo, a teoria crítica, deveria ter caráter emancipatório, criando formas de questionar esses métodos e libertar intelectual e socialmente a classe trabalhadora (Horkheimer, 1975). Horkheimer reforçou com isso um discurso alinhado ao de Karl Marx, onde a luta de classes é elemento central, porém, nesse caso, a fonte de libertação da classe dominada seria o pensamento crítico.

Compreendia-se que o cientista e sua ciência tradicional, estavam atrelados ao aparelho social e as pesquisas serviam à produção e não à autonomia dos trabalhadores. De acordo com a teoria crítica, a autonomia nos processos de trabalho seria uma ilusão de liberdade dos que 
estão sujeitos a economia burguesa (Horkheimer, 1975). Com isso, Horkheimer e Marcuse propuseram colocar as ciências sociais a serviço da investigação do conflito entre as forças produtivas e as relações de produção, cabendo à economia política ser a espinha dorsal dessa teoria e, junto com a psicologia e a teoria da cultura, formar a base da teoria crítica (Honneth, 1999).

Num segundo momento histórico do desenvolvimento da teoria crítica, Horkheimer e Adorno foram aos poucos abandonando uma estrutura centrada no capitalismo e no conflito de classes como proposto originalmente por meio de uma tradição marxista, e ao invés disso, centraram os estudos no processo civilizatório, no qual, por um processo histórico, o racionalismo instrumental empobrecia as capacidades sensuais da humanidade e contribuía para a formação de relações sociais de dominação, ou seja, o homem, ao aprender a dominar a natureza, aprendeu e se acostumou a dominar uns aos outros, o que então criou um ambiente fecundo para o seguimento, sem contestação até então, da teoria tradicional (Honneth, 1999).

Nesses dois momentos da teoria crítica, independente do foco na luta de classes ou com foco no processo civilizatório, o debate sobre emancipação não só se fez presente, mas foi central no desenvolvimento da teoria crítica.

\section{Conceito de Emancipação}

Para Alveson e Willmot (2010) a teoria crítica aborda a emancipação como um processo pelo qual os indivíduos se tornam livres da repressão social e condições ideológicas, ou seja, se tornam capazes de mudar a própria realidade. Porém, para os autores, teoria crítica não poderia ser simplesmente conectada aos estudos organizacionais e ao sistema de produção vigente. Seria necessário a reconstrução do ambiente, uma nova ordem que permitisse a emancipação dos indivíduos.

Logo, para proporcionar a emancipação, seria necessário um processo de criação de um ambiente novo e adequado para que os indivíduos consigam avaliar criticamente sua situação de trabalho por meio da autorreflexão e modificá-la, quando identificarem necessário, por meio da autotransformação, ou seja, deve dar condições ao indivíduo de refletir sobre, e modificar o ambiente onde está inserido (Alvesson \& Willmott, 2010). Portanto, a teoria crítica seria um instrumento para criar esse ambiente para a emancipação.

Contudo, os autores argumentam que a teoria tradicional nos estudos organizacionais compreende o objetivo emancipatório da teoria crítica de duas formas: a primeira rejeitando que a emancipação seja tema a ser discutido nos estudos organizacionais e a segunda 
relacionada a uma versão "soft", que concebe emancipação como tema que diz respeito à melhoria das condições de trabalho, satisfação, motivação, entre outros temas (Alvesson \& Willmott, 2010), e não a relacionando a um processo de libertação de indivíduos acríticos.

Logo em seu primeiro trabalho conceituando a teoria crítica, Horkheimer (1975) apresentou claramente que a teoria crítica possui caráter emancipatório, pois o homem deveria utilizar a razão e a crítica para deixar de ser um membro apático de um organismo, e que as categorias econômicas como o trabalho, valor e produtividade seria um idealismo que formam o mundo sob a ótica do capital, mas não é necessariamente bom para o homem, ou seja, a emancipação tem um caráter de transformação, não admitindo uma versão soft.

Habermas (1975), ao dividir em três categorias o processo de pesquisa relacionado ao saber, indica que no âmbito da ciência orientada pela crítica existe um interesse cognoscitivo libertador, ou seja, emancipador. Para Habermas, a crítica tem o objetivo de libertar, de emancipar o indivíduo de uma situação de privação, que ele, sem a crítica, não conseguiria identificar. Logo, também em Habermas, nada de "soft" seria concebível quanto ao tema emancipação na teoria crítica. Nesse sentido, a "frankfurtianidade" de Harbermas pode ser observada por seu alinhamento com os ideais emancipatórios fundadores da escola (Lara \& Vizeu, 2019).

No contexto europeu, o tema da emancipação teve grande evolução durante a primeira fase da escola de Frankfurt, quando a teoria crítica teve como referência de conteúdo a materialidade da vida, apresentando-se como um contraponto à teoria tradicional utilizada para exercer o domínio sobre essa materialidade. Nesse sentido, a teoria crítica deveria servir como um apoio para ações orientadas para emancipação, objetivando a transformação da ordem dominante geradora de miséria (Mizoczky \& Amantino de Andrade 2005a).

Horkheimer e Adorno consideravam que a emancipação estava relacionada a uma reconciliação do homem com a natureza, onde o homem, ao invés de dominá-la, aprenderia a conviver com a mesma e; cada vez que o homem tentasse dominá-la, caminharia em direção à alienação (Honnet, 1999), ou seja, o homem ao dominar a natureza que o abriga e sustenta, assumiria para si essa responsabilidade e a humanidade estaria propensa a ser composta por indivíduos que tentariam dominar uns aos outros.

Em prosseguimento aos trabalhos de Adorno, Habermas apontava que a ciência havia perdido a criticidade e contribuído para hegemonia de uma racionalidade técnica utilizada no desenvolvimento do capitalismo. A ciência é vista, então, como uma escrava da racionalidade, tendo-se voltado contra os seres humanos, também escravizados e dominados. Habermas, entretanto, abandona a materialidade como referência devido a sua percepção de que a 
emancipação da sociedade já não poderia ser expressa imediatamente em termos econômicos, dada a elevação do nível de vida inclusive das camadas mais amplas da população (Mizoczky \& Amantino de Andrade 2005a).

Na segunda fase da Escola de Frankfurt, dominada pela teoria da ação comunicativa, a emancipação passa a ser vista então de forma subjetiva, tendo como objetivo possibilitar equidade nas relações discursivas na esfera pública. Nessa fase a materialidade presente inicialmente no conceito de emancipação é totalmente abandonada e, em Habermas, o termo emancipação passou a não ter o mesmo sentido que em Horkheimer e Adorno (Mizoczky \& Amantino de Andrade 2005a), pois Habermas teria adotado emancipação sob o ponto de vista da subjetividade humana e Horkeimer e Adorno como processo de libertação dos indivíduos como proposto originalmente pela teoria crítica. Compreende-se que pode ser essa pequena diferença sobre o conceito de emancipação, a origem para o debate analisado nesse ensaio. Antes de analisar esse debate, faz-se necessário discutir brevemente o conceito de microemancipação apresentado no trabalho de Alvesson e Willmott (2010) publicado originalmente em 1992.

\section{Os Estudos Críticos em Administração e o Conceito de Microemancipação}

A emergência dos estudos críticos em administração ocorreu na década de 1990 com a decepção de teóricos em relação a expectativa de uma ciência administrativa composta por um conjunto de conhecimentos integrados à semelhança das ciências naturais. Essa frustração em relação à ciência da administração deixou os teóricos do campo e os próprios administradores mais atentos às limitações e deficiências nas práticas e nas teorias organizacionais, abrindo espaço para teorias que contestam as bases desse conhecimento, que convencionou-se chamar de estudos críticos em administração. O livro "Critical Management Studies”, de Alvesson e Willmott (2010), é considerado uma referência obrigatória, tendo consagrado essa expressão (Mizoczky \& Amantino de Andrade 2005).

O termo "crítica", apesar de parecer auto evidente, quando se refere aos estudos organizacionais, indica que existe algo de errado, seja na prática ou no corpo de conhecimento sobre gestão (Fournier \& Grey, 2000). E, sobre essa ótica, compreende-se que existiu a necessidade de modificar a concepção de gestão tradicional, ainda dominante, o que Horkheimer buscou desenvolver sob aspectos epistemológicos, mesmo que o termo crítico não tenha uma vinculação exclusiva e linear com a teoria crítica.

Os pesquisadores dos estudos críticos em administração foram influenciados por 
diversas tradições teóricas como o marxismo, pragmatismo e pós-estruturalismo, porém, apesar de não terem compromisso direto com o nome, grande parte dessa inspiração foi extraída da teoria crítica, em especial dos escritos de Adorno e Horkheimer na Escola de Frankfurt (Alvesson \& Willmott, 2010). Compreende-se então que a Teoria Crítica compõe, associada à outras correntes teóricas, a base epistemológica do que compreendemos hoje por estudos críticos em administração.

Mas, como podemos identificar os estudos críticos em administração? Miszoczky e Amantino de Andrade (2005a) apresentam dois caminhos: o primeiro seria verificar uma atitude filosófica alternativa ao positivismo dominante no campo da administração, tais como a hermenêutica ou pós-estruturalismo; o segundo seria a identificação dos trabalhos críticos com as múltiplas tradições intelectuais das ciências sociais, tais como a teoria crítica da escola de Frankfurt, o feminismo, entre outras correntes teóricas. A partir de Founier e Grey (2000) e Alveson e Willmot (1992) pode-se estabelecer três características compartilhadas entre os estudos críticos: visão desnaturalizada da administração; não performatividade e; ideal de emancipação.

Tendo argumentado que o processo emancipatório é incompatível com o contexto dos estudos organizacionais contemporâneo, Alvesson e Willmott (2010) concebem o conceito de microemancipação, que se refere a um processo de pequenas adaptações para maior aceitação da teoria crítica no mainstream dos estudos organizacionais. A Microemancipação seria embasada em atividades, formas e técnicas concretas como objetos e facilitadores para resistência que seriam veículos de emancipação. O objetivo é buscar brechas na gestão para evitar as formas de dominação e poder. A Microemancipação atua então num processo dialético entre controle e resistência buscando "quebrar" os movimentos de opressão com pequenas ações concretas que ajudam no processo emancipatório (Alveson \& Willmott, 2010).

A microemancipação enfatiza movimentos temporários e parciais que buscam afastar as diversas formas de opressão presentes na teoria e na prática organizacional, sem a busca por um ideal de emancipação plena. Nesse contexto, o termo microemancipação aproxima-se do pensamento de teóricos críticos que se afastam da utopia de transformação presente no marxismo ortodoxo (Alveson \& Willmott, 2010).

Embora os trabalhos de Alveson e Willmott (1992, 2010) sejam reconhecidos pela relevância para os estudos críticos em administração, a ideia de microemancipação gerou um debate entre autores do campo despertando críticas daqueles que consideram a incorporação do termo aos estudos críticos como uma forma de "crítica domesticada", nos termos de Mizoczky e Amantino de Andrade (2005a). Apresentamos resumidamente esse debate desenvolvido no 
contexto brasileiro.

\section{Debate Sobre Emancipação e Microemancipação}

Antes de propor o conceito de microemancipação, Alvesson e Willmott (2010) apresentam o ideal emancipatório da teoria crítica e uma série de críticas que, conforme argumentam, dificultam a ampliação da influência da teoria crítica nos estudos organizacionais, tais como, intelectualismo, essencialismo e negativismo. Assim, a ideia de microemancipação surgiu como uma proposta para superação dessas críticas e como caminho possível para que a teoria crítica ampliasse sua influência nos estudos organizacionais, tornando-se uma alternativa viável frente ao positivismo da teoria tradicional.

Mizoczky e Amantino de Andrade (2005a) apresentaram duras críticas à introdução da ideia de microemancipação como componente dos estudos críticos em administração. Nos países desenvolvidos, a emancipação não teria o mesmo significado que nos países de capitalismo tardio, uma vez que os níveis de miséria não são alarmantes ao ponto de despertar na sociedade o desejo de emancipação. As autoras argumentam que Alvesson e Willmott (2010) partiram de uma visão já restrita de Habermas sobre a emancipação para criar o conceito de microemancipação. Conforme já abordamos, Habermas argumentava que, devido ao avanço na qualidade de vida, mesmo das camadas mais amplas da população, a emancipação não poderia ser traduzida em sentido econômico, mas sim em um sentido subjetivo. Dessa forma, a proposta de Alvesson e Willmott (2010) poderia ter sentido nos países capitalistas avançados, mas pouco sentido teria ser difundido nos estudos organizacionais de forma geral, uma vez que a minoria da população mundial se faz presente nesses países centrais. Ou seja, o debate sobre microemancipação, para as autoras, não tem sentido em países onde as camadas mais amplas da população não usufruem dos benefícios econômicos visualizados por Habermas no contexto europeu.

Para reforçar a argumentação contrária à adoção da ideia de microemancipação como estudo crítico, Mizoczky e Amantino de Andrade (2005a) recorrem a autores brasileiros que, antes mesmo da emergência dos estudos críticos em administração, adotavam posturas críticas ao status quo dos estudos organizacionais. Citando Guerreiro Ramos (1989), por exemplo, as autoras questionam a intenção de simplificação da teoria crítica para aplicação no contexto dos estudos organizacionais. Motta (1985) é citado pelas autoras para destacar o posicionamento crítico em relação à hierarquia como componente central e indispensável para o exercício da dominação, criticando trecho do trabalho de Alvesson e Willmott (1996) em que os autores 
alegam que o papel da crítica não inclui uma aspiração de eliminação da hierarquia nas organizações.

Em resposta à crítica apresentada por Misoczky e Amantino de Andrade (2005), Alcadipani (2005) argumenta, de forma geral, que o Critical Manegent Studies (CMS) é um movimento plural com forte influência pós-estruturalista e que o conceito de microemancipação proposto por Alvesson e Willmott (2010) não pretende desconsiderar a contribuição da visão panorâmica e utópica da teoria crítica para o projeto de emancipação.

Detalhando sua argumentação em defesa da pluralidade dos CMS, Alcadipani (2005) rebate os quatro equívocos que, segundo Misoczky e Amantino de Andrade (2005), são cometidos pelo movimento estrangeiro. Na percepção de Alcadipani (2005) a proposta de microemancipação não se contrapõe ao projeto utópico da teoria crítica, mantem uma postura opositora às concepções dominantes e às suas práticas, denuncia as soluções remediadoras adotadas no contexto organizacional e, por fim, ao criticar características da teoria crítica, como intelectualismo e essencialismo os autores não culpam os frankfurtianos. Alcadipani (2005) ainda argumenta que, a partir de uma perspectiva teórica marxista revolucionária ou fundamentalista é possível atribuir aos CMS um viés reformista. Entretanto, desta perspectiva, qualquer relação com o mundo da gestão seria condenado.

Em resposta, Misoczky e Amantino-de-Andrade (2005b) apontam que a pretensa pluralidade do movimento CMS deve ser vista com cautela, pois "o pluralismo, quando se torna uma ideologia, relativiza a legitimidade da contestação feita do ponto de vista daqueles que são estruturalmente subordinados". Assim, argumentam que o questionamento do pluralismo absoluto como verdade única deveria ser uma tarefa dos intelectuais, tomando como práxis o fazer acadêmico.

Quatro anos mais tarde, o trabalho de Paes de Paula, Maranhão e Barros (2009) retoma esse debate tendo como foco o questionamento sobre o pluralismo do movimento CMS e os riscos de uma crítica alinhada com o "gerencialismo engajado". Nesse trabalho os autores alertam para um equívoco que vinha, conforme argumentam, se tornando comum nos CMS: o uso distorcido da ideia pós-estruturalista de microemancipação para defender ações de gerencialismo engajado. Apontam que Spicer, Alvesson e Kärreman (2007), por exemplo, embora vejam a possibilidade de microemancipação nas organizações, ignoram a possibilidade de transformações mais radicais. Paes de Paula, Maranhão e Barros (2009) não rejeitam a ideia de microemancipação, mas argumentam que essas microresistências não tem sentido fora de um contexto de uma mudança no sentido sistêmico. Assim, argumentam que Spicer, Alvesson e Kärreman (2007) sabotam a ideia de resistência abrindo espaço para seu uso ideológico, 
sugerindo que essas microresistências podem ser usadas para um gerencialismo engajado.

Esse instigante debate certamente contribui para compreensão da formação e de limitações de um campo de estudo, bem como as convergências e divergências que nos permite, sem a precisão matemática, vislumbrar as fronteiras abertas dos diferentes campos dos estudos organizacionais.

\section{Considerações Finais}

Como no próprio estudo de Alvesson e Willmott (2010), compreende-se que as lutas locais podem melhorar temporariamente o ambiente, mas é necessário tratar a questão de maneira estrutural, buscando resolver a causa raiz. Como apresentado, os autores deixam uma pista de que a microemancipação pode não ser suficiente para solução de questões estruturais, não devendo, contudo, ser negligenciada no papel histórico e macroprocessual da prática organizacional. É importante salientar que, quando os autores introduzem o conceito de microemancipação, não estão, em nossa análise, re-significando o conceito de emancipação, estão apenas incluindo um novo elemento em favor da crítica e dos processos emancipatórios.

Compreender que, para países de capitalismo tardio, o debate sobre microemancipação é inadequado, como proposto por Misoczky e Amantino de Andrade (2005a), consiste em concordar que o debate não cabe em um momento histórico regional e isso não é suficiente para rejeitar o conceito de microemancipação. Os próprios autores, Alvesson e Willmott, relatam que não é possível simplesmente conectar a teoria crítica aos estudos organizacionais, ou seja, é necessário um processo de reconstrução do ambiente, e a microemancipação poderia ser um instrumento para auxiliar em tal mudança.

Quando Alvesson e Willmott (1992) classificam a emancipação em tipos e focos, eles declaram abertamente que não rejeitam e nem modificam o conceito utópico de emancipação. O estudo de Alvesson e Willmott (2010) tem um foco incremental e reformista, pois o objetivo do artigo foi responder algumas críticas dos pós-estruturalistas referentes ao intelectualismo, essencialismo e negativismo e não pretendia ressignificar o conceito de emancipação.

Nesse sentido, a adoção ou aceitação do conceito de microemancipação nos estudos críticos não implica, necessariamente, na negação do ideal de emancipação, a substituição ou deturpação desse conceito ou o desligamento de um objetivo mais amplo de transformação. Embora, conforme alertado por Paes de Paula, Maranhão e Barros (2009), seja necessário atentar para os riscos de envolvimento em um gerencialismo engajado, utilizar os espaços abertos para a crítica na teoria e na prática organizacional não pode ser desqualificado como 
crítica.

Compreende-se que o debate em torno do conceito de microemancipação é importante e saudável e o ato de debater está no cerne da teoria crítica, logo cabe exaltar esse processo dialético entre os renomados autores. É válida a crítica em torno da utilização desse conceito como forma de subversão da ideia de emancipação tão cara à teoria crítica, porém, como demonstrado por aqueles que criticam esse ponto, essa subversão ocorre em alguns trabalhos que contrariam a própria concepção do conceito de microemancipação.

A ideia de microemancipação pode ser (e tem sido por alguns autores) utilizada de forma prejudicial ao propósito emancipatório da crítica. Porém, é importante destacar que o problema não está no conceito em si, pois a apropriação e deturpação de conceitos ocorrem em diferentes contextos. Ademais, não se pode conceber a teoria crítica como a prescrição de um único caminho possível para emancipação. A própria tradição da escola de Frankfurt aponta para a necessidade de um processo de constante reflexão sobre a teoria tradicional, mas também sobre a própria teoria crítica.

\section{Referências}

Adorno, T. W. (1975). Negative Dialektik. Fráncfort: Suhrkamp; trad. Dialéctica negativa. Madrid: Taurus.

Alcadipani, R. (2005). Réplica: a singularização do plural. Revista de Administração Contemporânea, 9(1), 211-220.

Alvesson, M., \& Willmott, H. (1992). On the idea of emancipation in management and organization studies. Academy of management review, 17(3), 432-464.

Willmott, H. (1996). Making sense of management: a critical introduction. Sage Publications.

Alvesson, M., \& Willmott, H. (2011). Critical Management Studies, 4 vols. London, CA: Sage.

Bertero, C. O. (2011). Réplica 2-o que é um ensaio teórico? Réplica a Francis Kanashiro Meneghetti. Revista de Administração Contemporânea, 15(2), 338-342. 
Corley, K. G., \& Gioia, D. A. (2011). Building theory about theory building: what constitutes a theoretical contribution?. Academy of management review, 36(1), 12-32.

Fournier, V., \& Grey, C. (2000). At the critical moment: Conditions and prospects for critical management studies. Human relations, 53(1), 7-32.

Habermas, J. (1975). Conhecimento e interesse in: Escola de Frankfurt. Os Pensadores.

Honneth, A. (1999). Teoria Crític. In: GIDDENS, A.; TURNER, Jonathan (Orgs.). Teoria social hoje. São Paulo: Unesp.

Horkheimer, M. (1990). Teoria crítica: uma documentação. Tradução Hilde Cohn.

Horkheimer, M (1975). Teoria tradicional e teoria crítica. In Teoria tradicional e teoria crítica. Os pensadores. São Paulo: Abril SA Cultural e Industrial.

Lara, L. G. A., \& Vizeu, F. (2019). O potencial da frankfurtianidade de Habermas em estudos organizacionais. Cadernos EBAPE. BR, 17(1), 1-11.

Meneghetti, F. K. (2011). O que é um ensaio-teórico?. Revista de Administração Contemporânea, 15(2), 320-332.

Misoczky, M. C., \& Amantino-de-Andrade, J. (2005a). Uma crítica à crítica domesticada nos estudos organizacionais. Revista de Administração Contemporânea, 9(1), 193-210.

Misoczky, M. C., \& Amantino-de-Andrade, J. (2005). Tréplica: quem tem medo do fazer acadêmico enquanto práxis?. Revista de Administração Contemporânea, 9(1), 237-243.

Paula, A. P. P. D., Maranhão, C. M. S. D. A., \& Barros, A. N. D. (2009). Pluralismo, pósestruturalismo e" gerencialismo engajado": os limites do movimento critical management studies. Cadernos Ebape. BR, 7(3), 393-404.

\section{Porcentagem de contribuição de cada autor no manuscrito}

Leonardo Alexandrino de Almeida - 50\% 
Research, Society and Development, v. 9, n. 4, e167943052, 2020

(CC BY 4.0) | ISSN 2525-3409 | DOI: http://dx.doi.org/10.33448/rsd-v9i4.3052

Richardson Moro Schmittel - 50\% 